\title{
Margaret Hasluck, 1885-1948
}

\section{Hyjni Ceka}

Përpara inteligjencës shqiptare, qëndron detyrimi moral për ndritjen e figurës së shkencëtares angleze, Margaret Hasluck. Kjo barrë, më shumë, u takon intelektualëve elbasanas, jo për tjetër gjë, po ngaqë anglezja e famshme, duke banuar për 13 vjet në Elbasan, i dha emër të mirë qytetit tonë, kudo në botë.

Ka qenë një kohë, kur historia e qytetit u lidh ngushtë me jetën e kësaj zonje të nderuar. Si padashur, emri i saj u përjetësua nëpër rrugë e ndërtesa, por edhe nëpër lule e pemë.

Në fëmijëri ne dilnim për shëtitje me shkollën nga "Rruga e Englezkës", shihnim “Vilën e Englezkës”, laheshim te "Rema e Englezkës”... Ndërsa nëpër oborre, mbanim trëndafila të "englezkës” e rritnim mollë nga të sajat.

Po erdhi një kohë, më vonë, kur s'na linin ta zinim me gojë Gretën tonë... dhe, pastaj zunë të na e denigrojnë e t'i ngjisnin lloj-lloj bishtash... E kush e bënte këtë?... Enver Hoxha dora-vetë! Diktatori i kuq shkonte e merrej me punët më të ndyra!

Për çudi, në radhët e pleqve ardhacakë, ka të tillë që, edhe sot, për Hazllëkun (Hasluck), flasin “hudhra më kungull'. Sigurisht, ngaqë nuk kanë patur rast ta njohin e t'i lexojnë veprën e gjerë në të mirë të kombit tonë.

Prit e prit..., se mos ndonjëri prej të diturve me tituj, dilte përpara auditorit të gjerë dhe ligjëronte për trashëgiminë e Hazllëkut...

S’u bë gjë!

Nisa vetë pastaj, të hulumtoj e të qëmtoj ndër libra e periodikë... T’u jap bashkëqytetarëve të mi këtë trajtesë modeste për zonjën Margaret Hazllëk. Të heq atë baltë të pistë që hodhi " $i$ paudhi” mbi këtë figurë fisnike e mendjendritur. 


\section{Albanon}

\section{Revistë kulturore}

Margaret Hazllëk, ishte e bija e një bujku skocez, Xhon Mardie (John Mardie).

Pra, kot e paskemi thirrur "Englezkë". Dhe, çudi si e paska duruar ajo, sepse dihet që skocezët përkatësinë kombëtare e mbrojnë me fanatizëm dhe nuk pranojnë assesi t'ua ngatërrosh.

Lindi më 1885... Vitet e para të fëmijërisë së saj, i kaloi në Moraishirë (Morayshire). Ka qenë e hardhueshme, shkruajnë biografët dhe inteligjenca e mprehtësia e saj ranë në sy qysh në moshë të adoleshencës... Gjithë kjo, bëri që vajza e vogël e fermerit të thjeshtë, Xhon Mardie, të ndiqte mësimet në njërën prej shkollave të mesme më në zë të vendit, me emrin sinjifikativ "Elgin Akademi".

Dhe... në mbarim të shkollës, përfundime të shkëlqyera!

Ajo ishte nga ato mendje të ndritura që i bënin vend vetes dhe siguronin hapjen e dyerve të dijes. Kreu dy fakultete, njërin pas tjetrit. Studioi në Universitetin e Aberdinit, më së pari, ku përfundoi studimet më 1907, duke u diplomuar në degën klasike. Për të kompletuar përgatitjen intelektuale, do të kalojë më pas në të famshmin Universitet të Kembrixhit, ku doli, si gjithnjë, me rezultate të shkëlqyera, duke dhënë provimet e Tripos (pjesëmarrje në testim për studentë fenomenalë).

E pajisur me bagazh diturie, e gatshme t'i shërbejë lavdisë së atdheut, niset si misionare për të përhapur në trevat e Lindjes, kulturën anglo-saksone... Që nga koha e Bajronit dhe e Eduard Lirit, në Britaninë e Madhe qe kultivuar tendenca ekzotike për t’iu përkushtuar Heladhës. Kjo përpjekje shoqërohej me kuriozitetin për Botën Homerike dhe për letërsinë e helenëve të lashtë. Gjithë këto motive e nxitën Margaretën të niste punën si pedagoge në British School (në Shkollën Britanike të Athinës).

Kultura e gjerë e profesoreshës së re, bie në sy me të parët. Që në fillim, ajo tërhoqi vëmendjen e nëndrejtorit të kolegjit, zotit F.W. Hazllëk (Hasluck).

Ç’ishte F.W. Hazllëk?

Etnograf nga më të dëgjuarit!... Përjetësuar nëpër fjalorë dhe enciklopedi me veprën "Manastiret e Malit Athos".

Margareta 27 vjeçe, më 1912, do të lidhë jetën me zotin Hazllëk dhe me shkencën e etnografisë. Si romantike e përkushtuar, ajo do t’i bëhet krah i djathtë të shoqit, këtij savanti të shkëlqyer, që përmbështolli nëpër libra gjithë traditën kishtare në "Ajos Athos". Por lumturia bashkëshortore e Margaretës nuk do të shkëlqejë gjatë. Më 1916, pikërisht katër vjet pas martesës, profesori 
do të sëmuret nga mushkëritë. Të dy ata, u shpërngulën në Zvicër, ku zoti Hazllëk iu nënshtrua kurimit... Mjekimi nuk qe i suksesshëm... Kështuqë Magareta, në moshën 35 vjeçe, ngeli e ve.

Me këmbënguljen burrërore, me kurajon e së pathyeshmes, zonja Margaret do të kthehet në Angli, gjakftohtë tamam si gjithë britanikët, trimëreshë veçan si skocezët, do të përfundojë veprën e plotë "Manastiret e Malit Athos", të cilën e boton në emër të të shoqit.

Mbasi i siguroi zotit Hazllëk një përjetësim dinjitoz, ajo nis të mendojë për përjetësinë e vet.

Angazhimi me veprën e burrit, qe shtysë për të që të interesohej për kulturën tradicionale të Ballkanit në përgjithësi. Kureshtja shkencore, mendjen e saj e drejtoi në Shqipëri, ku lulëzonte një folklor dhe një kulturë popullore, e njohur pak në Britani, gjer më atëhere.

Është rasti të vëmë re, se demokracitë e stabilizuara, bëjnë dekada vitesh që e kanë vënë në binarë sponsorizimin e punës krijuese, shkencore qoftë apo artistike. Kështu, në Angli, funksionojnë institute të posaçme që financojnë projektet intelektuale të individëve... Njërit prej këtyre iu drejtua Margaret Hazllëk, pikërisht Wilson Traveling Fellowship... Në këtë mes, rol të veçantë luajti vepra "Manastiret e Malit Athos", që kish marrë nam e kish bërë bujë. Menjëherë iu akordua një fond i majmë, si bursë për të nisur hulumtimet... E siguruar mirë nga ana financiare, vendoset drejt e në Elbasan, në fund të vitit 1927.

Nuk dimë se kush ia rekomandoi Elbasanin, po ç’është e vërteta, qyteti ynë, asikohe, mbahej për vend i qetë, mikpritës, i kulturuar, por edhe trevë mjaft interesante, përsa u përkiste traditave e zakoneve fisnike.

Duke ardhur këtu, ajo shpejt bëri mend të vendosej për fare... Në fund të vitit 1930, e kish ngritur vilën e saj në rrethinat e qeta të Elbasanit. Banesa i shkonte gjithë sarajet e bejlerëve... E kish lidhur me rrugë dhe pajisur me gjithë komoditetet... Përpara lulishte trëndafilash, pas pemishte, kudo mollë e dardhë përzier... Rrethuar me kangjella, që njerëzit ta shihnin: Evropë ballë për ballë. Të shihnin dhe jetë të kulturuar nëpër ambiente të hapura...

Dhe hyri e doli në Elbasan, kudo, shtëpi më shtëpi. Dhe u mahnit me Elbasanin, se gjet këtu njerëzit më të mirë të botës, të edukuarit, të moralshmit, shpirtmëdhenjtë... Vjedhja nuk njihej... smira jo... E bënte të gjithë pasja dhe begatia! Të krishterë e myslimanë, bashkë të përqafuar... Ajo çuditej. Kujtonte Britaninë e saj, ku protestanë e katolikë - si macet me minjtë... 


\section{Albanon}

\section{Revistë kulturore}

Qe grua kapedane që hulumtoi, si rrallëkush. Në shkencë... burrat i linte pas. Të ishin ç'të ishin! Këtë njeriu e vë re tek studion veprën e saj madhore "E drejta e pashkruar në Shqipëri”.

Në libër është pasqyruar Shqipëria Veriore, që nga Krasniqja e Malësisë së Gjakovës, deri në Kelmend të Malësisë së Madhe, Kthella e Mirditës, Zadrima e Bregut të Matës, Luma e Dibra, Kurbini e Kruja, Shëngjergji e Martaneshi, Gurakuqi e Shmili, Pezë e Ndroq, Zhullimë e Krrabë.

E mendoni Shqipërinë e atyre viteve! Margareta, ardhur prej anës së anëve, bredh këtë vend, herë më këmbë e herë kaluar, qafë më qafë e va më va. E preokupuar sa më s'ka, sepse Kodi Civil në Shqipëri i mënjanoi fare Kanunet dhe "E drejta e pashkruar" është rrezik të humbë e të harrohet, si shumë vepra të tjera të kulturës popullore shqiptare. Me një përkushtim të habitshëm, ajo do të mundë t'ia dalë në krye, ta zbulojë të plotë legjislacionin tradicional të shqiptarëve, ta konservojë, ta komentojë, duke e ilustruar me mijëra shembuj që i hasi vetë, që i nxorri vetë nga kujtimet e "pleqve" të kanunit... Gjithë këtë mund ta bënte një mendje gjeniale, një shpirt human që vë hall për monumente të njerëzimit, të çdo populli qofshin... Këtej nxjerrim përfundimin se Hazllëku nuk ndjeu çaste prehjeje, nuk gëzoi vilë e komoditete... Sa rrojti në Shqipëri, e shkoi nëpër udhë jetën, duke gjurmuar visaret e kombit tonë... Elbasanasit do ta shihnin buzë pranvere të nisej me karvane qiraxhinjsh... Kur kthehej rrëzë dimrave, kuajt ngarkuar me arka. Ç’ishin ato arka? Sepete nusesh (mbushur dinga). Jo me pajë e qëndizma çupash..., po me pllaka fotografike, të asaj kohe, ku ishte fiksuar gjithë kultura popullore shqiptare.

E... në atë vepër, që u shkrua mbi atë material, jeta shqiptare do të mund të jepej gjer në detaje të imëta. Sigurisht, me gjithë mekanizmat që e drejtonin atë, me "Kodet e Traditës"... Prandaj dhe libri mori titullin "E drejta e pashkruar në Shqipëri”.

Kam pasur rast ta lexoj "Kanunin e Lekë Dukagjinit", por dhe studime të tjera mbi të drejtën zakonore, "Shartet e Idriz Sulit”, për shembull, "Must Ballgjinin” etj. Por në veprën e kësaj shkencëtareje vitore, ka diçka të veçantë. Në radhë të parë, mënyra e të shkruarit. Në faqet e librit mplekset narracioni shkencor, me atë artistik... Stil që do ta bëjë të vetin te ne vetëm prof. Dh. S. Shuteriqi, më vonë.

Libri përmban 25 kapituj, po do t’ju përmend veç dhjetë të parët, që të krijoni një ide sidokudo për gjithë brendinë e tij. 
1. Shtëpia shqiptare

2. Familja shqiptare

3. I zoti i shtëpisë

4. Ndarja e vëllezërve

5. Ligji i qenit

6. Udhët

7. Kufijtë

8. Kullotat

9. Bajraktarët

10. Pleqtë

... Pra, Shqipëria e traditës... Shqipëria në histori... me kodet e veta, që i kishte rezistuar Sheriatit dhe invazionit osman për radhë, pesë shekuj.

Mua, ajo që më lë pa mend te Hazllëku, është studimi i thelluar... Kur flet për zbatimin e së drejtës së traditës, ajo sjell mori rastesh, në mori vende, se si janë gjykuar prej "pleqve” shkelje kanuni nga më të ndryshmet... të kohës që ka studiuar vetë ajo, po dhe të njëqind vjetëve përpara... Këtë e bën me një stil tërheqës..., se shembujt na i thotë në formën e meseleve... Nga kjo anë, Hazllëku është e para që mbledh anekdotat e Binak Alisë, nga Krasniqja e Malësisë së Gjakovës, të Must Ballgjinit nga Gurakuqi, të Selim Peshkut nga Martaneshi.

"Englezka" nuk mbetet brenda qerthullit të etnografisë... Në veprën e saj, ajo nxjerr përfundime dhe jep mësime për zhvillimin e mëtejshëm të jetës shqiptare. Sa etnografe, ajo është dhe sociologe... Në kapitullin për "Bajraktarët”, e gjen me vend politikën e Zogut për të neutralizuar parësinë e bajraqeve. Ky institucion nuk i shkon më Shqipërisë që ka marrë rrugën drejt Evropës. Mbajtja larg e "krerëve", kompensimi i pushtetit të tyre me grada oficerësh rezervë, ngelet një gjetje e përkryer për kohën... Këtu Hazllëku bën kujdes të thotë fjalë të mira për sovranin, që po zhduk imazhin medioval të Shqipërisë dhe po mundohet me ç’i vjen për dore... të krijojë një shoqëri të emancipuar.

... Nëse ndala tek “E drejta e pashkruar", e bëra këtë për të mëshuar në veprën kryesore të saj e ta drejtoj këtu vëmendjen e lexuesit... Po Englezka, kur nisi të merrej me shkencat albanologjike, e zuri me gjuhësinë në krye. Më 1932 do të botonte veprën e parë, me emër të vet, "Albanian-English Reader" (Këndim anglisht-shqip). 


\section{Albanon}

\section{Revistë kulturore}

Po ka qenë dhe poeteshë, se ka qëndisur ca peizazhe artistike në gjuhë shqipe, sa na i la pas krahëve stilistët tanë të viteve '30, që të tërë... Le që janë disa përshkrime për pyjet e Ballenjës e ca të tjera për Tomorricën dhe Tomorrin që të shastisin fare... Të gjitha këto i botoi tek "Shkolla Kombëtare". Eqrem Çabej bëri punë të mirë, më 1943, kur i mori dhe i përmbështolli perlat e saj letrare në antologjinë dinjitoze, "Bota shqiptare”.

... Duke qenë se Shqipërisë i kërcënohej invazioni fashist, Hazllëku, në shkurt të 1939-ës, largohet nga Elbasani. Vendoset në Athinë, hë për hë. Atje ku pat kaluar dikur nusërinë dhe jetën bashkëshortore... Po qielli i Ballkanit u mbyll e u nxi më të katër anët. Hazllëku u mbart për në Aleksandri atëhere... dhe, pastaj, në Kajro. Gjithë kohën e Luftës së Dytë Botërore, atje e kaloi, në Egjipt.

Ishte afër mendsh që, në çastet kur demokracia dhe obskurantizmi ngërtheheshin fytafyt, Hazllëku mbante nga krahu më progresiv. Kësaj radhe, jo si muhaxhire ngelur rrugëve, por si ushtarake graduate, pranë një shtabi autoritar, siç ishte ai i Mesdheut. Me cilësinë e shkencëtares etnografe, instruktonte grupet dhe njësitë e komandove, përpara se të desantonin në Greqi dhe Shqipëri, për të ndihmuar vatrat e rezistencës antifashiste. Atje pat qëlluar që pat udhëzuar dhe gjeneralin Dejvis me shokë, kur niseshin për në Shqipëri. Por u pat mësuar etnografi dhe jo spiunazh... Kapedania Margaret, i entuziaste kursantët tek u fliste për fisnikërinë e shqiptarëve, për trimërinë dhe mikpritjen... U jepte krahë ushtarakëve britanikë, para se të vinin këndej për çlirimin e Shqipërisë nga fashizmi... Niseshin gjithë gaz... Kur zbritnin në tokë shqiptare, i pritnin buzët e Enver Hoxhës, të varura naa, dy pëllëmbë. Dhe "shejtani me brirë" do të shkruajë "vepra” më vonë. Heroizmën e katranosi pastaj. Fisnikërinë e përdhosi. Miken e quajti armike. Shkencëtaren... spiune. Na bëri hasm me të tërë. Na qorroi... Na shushati.

... I djallëzuari është rrokur dhe mbas një huri tjetër për ta marrë nëpër gojë Hazllëkun... Te miqësia e saj me Lef Nosin... Veç ky zbulim mjafton "për ta zhveshur lakuriq" Enver Hoxhën. Shpirtgrymti nuk arriti ta marrë me mend se ka njerëz që miqësohen prej idealesh intelektuale-humane... Miqësia midis Lefit dhe Hazllëkut ishte më e bukura e botës... Më fisnikja... Mëkat! S’u gjend artist të shkruante për të!... Por e la, sa erdh dhe e përfoli Enver Hoxha!

Atë kohë që u ngul në Elbasan Hazllëku, Lef Nosi bënte mote që kishte lënë veprimtarinë politike dhe ndihte Shqipërinë me dritë e dituri... Ai qe bashkuar me lëvizjen intelektuale që vendosi bazat e studimeve shqiptare. 
Këta iluministë qenë hedhur në përpjekje për mbledhjen e kulturës sonë popullore, të folklorit në radhë të parë, të dokumentacionit historik, të traditës, në çdo fushë të jetës... Lefi, që pat redaktuar "Tomorrin” gjatë Rilindjes së vonë, në vitet e pavarësisë nxirrte periodikët "Kopshti letrar" e “Dokumente historike”... Më pas do të botojë dhe "Këngë kombiare". Dalja në dritë e këngës për Luftën e Kosovës është meritë e këtij zotërie... Ai e pat botuar së pari... Në "Kopshtin letrar" pa dritë dhe Gjorg Golemi, Petro Petroshi, Isuf Qosja dhe Qorr Topuzi... Aty u shkrua për luftën e Mlizës, për inkursionin e Skënderbeut nëpër grykë të Zaranikës etj... Atë kohë që vendosej ndër ne, Hazllëku, kish arritur shkallën më të lartë të perfeksionimit në fushën e studimeve. Pat një përvojë 15-vjeçare hulumtimesh. Ishte bashkautore në një vepër shkencore me dinjitet. Për gjithë këtë, në rrethet intelektuale të Elbasanit u mirëprit, ngaqë sillte metodikat e gjurmimeve shkencore.

Asaj iu desh miqësia e Lefit. Ai qe ndër njohësit më të mirë të jetës shqiptare. $\mathrm{Si}$ politikan e publicist, kishte informacion të saktë mbi psikologjinë shoqërore të bashkëkombësve, për zakonet në përgjithësi dhe kanunet e veçanta që drejtonin rrjedhat sociale, nëpër trevat e ndryshme të Shqipërisë... Objeksionet e veprës madhore, sigurisht, ajo i hartoi në konsultim me Lefin. Itineraret e ekspeditave të veta, i caktonte po me të. Gjithë bibliografinë e dokumentacionit që i duhej, pos Lefit s'kishte kënd tjetër që mund t'ia siguronte... Se dihej qëai ishte nëShqipëri bibliofil e bibliograf njëkohësisht..., por nga ata që s'ia gjeje kund shoqin.

Hazllëku, nga ana e saj, i dha drejtimin shkencor punës hulumtuese të Lef Nosit. Zgjoi preokupimin për arkivimin sistematik të dokumentacionit historik... Kryesisht për atë që rrezikohej të humbte nga mosvlerësimi. Ishte Englezka vetë që e nxiti atë të përqendronte ç'qenë monumente letrare të shpërndara. Atë kohë u shtinë në dorë kodikët e famshëm të esnafëve, "Psalltiri" i Anonimit, fragmentet e Todhrit, dorëshkrimet e Shijonit, regjistrat e Mitropolisë. Mbas 1927-ës, Lefi ngriti zyrat e veta, ku punonin përkthyes të osmanishtes dhe të greqishtes bizantine, kopjues e fotografë... Ai krijoi muzeun e tij dhe fototekën, bibliotekën dhe arkivin që, në Shqipëri qenë nga më të përsosurit.

Ç’është e drejta, këtu do theksuar se vërtet Hazllëku ndihmoi me udhëzimet e veta, po në ngritjen e asaj biblioteke të pashoqe, në krijimin e atij arkivi të pasur u derdh mund dhe paraja e madhe... S'qe veç përkushtimi i Lefit aty..., po i tërë Nosëve..., sidomos i Grigorit që e zgjidhi qesen e iu përgjigj vëllait me ç'kërkoi. 


\section{Albanon}

\section{Revistë kulturore}

... Tashti kthehemi dhe njëherë te "miqësia e përfolur"... Kur largohej prej nesh, Hazllëku, i besoi Lefit gjithë materialin e saj arkivor, shtëpinë dhe pasurinë... Dhe ai ia ruajti si sytë e ballit... Për vete s'u kujdes aq, po amanetin e Englezkës e siguroi në kasafortat e Bankës Kombëtare, kur në Shqipëri përmbysej çdo gjë.

... Gjatë Luftës, edhe pse qenë shokë në shkencë, nuk mbajtën qëndrime të njëjta... Lefi i besonte fort Hazllëkut, por jo dhe aq politikës angleze. Se ç'thotë Enver Hoxha pastaj, janë profka... Për Lefin, Shqipëria ishte mbi gjithçka.

Prapë se prapë, si qytetare e një vendi aleat, Margaret Hazllëk bëri çmos për të shpëtuar mikun shkencëtar nga vdekja... I shkroi dhe letër drejtpërdrejt Enver Hoxhës... Satanai, jo që s'e fali, po e vrau dhe nxori përrallëza që tregojnë sot pleqtë ardhacakë rreth kaloriferëve.

Ruajna nga i ligu, o Zot!

Desha t'ju ndris dhe diçka, së fundi!

Jetën e Hazllëkut nga '46-ta e më pas.

Përgjigjja arrogante e Enver Hoxhës për lutjen e Hazllëkut, u dha në shtyp dhe në emisionet e Radio-Tiranës. Nuk shkoi java dhe Lef Nosi u pushkatua... Kjo u trumbetua si arritje e madhe e Shtetit të Demokracisë Popullore.

Margareta këtë e mori për sfidë ndaj saj. Iu zgjuan strese pastaj, që e dërrmuan shpirtërisht. Ndiente sikur të zezën ia bëri ajo mikut të saj. " $K u$ vajta e ndërhyra, se nuk ishte për t'u vrarë Lef Nosi?'

Dhe na u sëmur rëndë... Iu shpif leucemia...

... Këto ngjanë në Kajro, në verën e nxehtë të 1946-ës.

Me shpresë se do të shërohej, shkoi në Qipro, po qe e detyruar të pranonte faktin se nuk kishte shumë kohë për të jetuar.

Ato çaste të rënda, iu zgjua preokupimi për librin, se vepra " $E$ drejta $e$ pashkruar" nuk qe zënë me dorë... Vërtet e pat mbledhur materialin, pat hartuar konspektet e kapitujve radhë, po lufta e pat ndarë nga puna studimore. Në rrethana të tilla, vdekja s’ishte gjë përpara humbjes së veprës. Hazllëku e harroi fare leuceminë.

Gjykoni tashti... të kesh halle koke, e t’i hedhësh pas krahëve! Të rropatesh për të nxjerrë në pah gjenialitetin e një kombi që, fundja, s’është yti. Gjithë 
kjo s’ishte tjetër, veç sakrificë altruiste që mund të bëjnë njerëzit më humanë të botës, shkencëtarët dhe artistët e vërtetë.

Vendosi të kthehej në atdhe me mendje të mbledhur, të nxirrte në dritë studimet e veta.

Punë e parë iu drejtua Leverhulmit (Leverhulme Research Fellowships Trust). Atje u zbraz dhe shfaqi brengën... Dhe zemërgjerësia s’i ka munguar botës asnjëherë! U gjendën njerëz në çast ta ndihmojnë Hazllëkun, që të bënte atë heroizëm human në ditë të fundit të shpirtit.

Fondacioni i bursave u vu i tëri në lëvizje. Veprimet u kryen me urgjencë e korrektësi. Çdo punë në kohë të vet e në vend të vet. Hazllëkut ia përgatitën rezidencën në Dublin, qytet i qetë, larg zhurmës politike të pasluftës. Rreth zonjës së nderuar u caktua një ekip i kompletuar me specialistë të shkencave etnologjike, i kryesuar nga I. E. Andersen. Veç kësaj, albanologë të ndryshëm, miq të Shqipërisë, do të vizitonin Margaretën herë pas here. Hazllëku u pat hyrë studimeve normale, me dëshirë të madhe pune, kur e kur e entuziazmuar nga sukseset shkencore. Kuraja e mahnitshme dhe këmbëngulja për të përfunduar me gjallje veprën, mund të vlenin si shembull i rrallë për kuriozët, po në ato pak ditë jete që i mbetën, s’kishte si përfundohej gjithë ajo punë e vëllimshme. Hazllëku bëri një përpjekje me mend atë kohë që angazhoi I. E. Andersenin në të gjithë detajet e veprimtarisë së vet shkencore. Andersenit iu bë i njohur krejt materiali, i mbledhur në Shqipëri, skicat e planit të librit, titujt e projektuar të kapitujve... Dhe ndërkohë, Greta vazhdoi të shkruante, sikur asgjë nuk do të ndodhte. Përfundoi dhe kapitullin e katërt të librit. Kur hidhej në të pestin, ajo mbështeti kryet mbi fletët e dorëshkrimit. Kujtoi se ishte lodhja që e këputi... po, kishte qenë vdekja, që e mori në gjirin e vet, si pa kuptuar.

Kështu qëllon që mbyllin sytë apostujt-shërbëtorët e devotshëm të njerëzimit. Përkushtimi në punë s'lë kohë për ta çuar mendjen te vdekja. Fundja, përse ta çosh, kur ndër vepra, ngelesh gjallë për jetë të jetëve.

Kjo ngjarje e vitit 1948, në Shqipëri s'u mor vesh fare... Sikur të ish lajmëruar, në Elbasan do të gjendeshin aq zonja e zotërinj që do ta mbushnin me lule pragun e Englezkës, në mes të Arave të Gjata.

Kështu iu nda Shqipërisë njëra prej mikeve më të ngushta. Të kish ndodhur ndër ne fatkeqësia, humbja patjetër do të ishte katastrofë. Me njeriun bashkë do të kalbej dhe vepra në varr. Po ndodhi në Britaninë e Madhe, në djep të qytetërimit... atje ua dinë vlerën thesareve të kulturës, ndaj s'u shfaqën probleme... Sikur të mos kishte ndodhur gjë fare, hartimi i librit kaloi nga një palë duar, në të tjera... as më shumë e as më pak... po aq të shkathta. 


\section{Albanon}

\section{Revistë kulturore}

Çojeni mendjen, ku e ndërpreu punën Hazllëku! E thamë më sipër... te kapitulli i katërt... Që aty e deri në të njëzetepestin, i shkroi Anderseni, sikur t'i shkruante një dorë... Po me atë bukuri stili, me atë thellësi mendimi, sa nuk gjendet kritik në botë që të dallojë ku e la Hazllëku e nga e zuri Anderseni.

Ka artistë bota!

Artistë po se po, por edhe shpirtmëdhenj. Vazhdon tjetri veprën e nuk vë fare emrin mbi kopertinë të librit! As si bashkautor të paktën! Përse? Sepse materiali i mbledhur është i tjetërkujt.

Pra, njohëm dhe Andersenin me këtë rast, shkencëtar i shquar, zemërgjerë i pashoq, mik me kokë i Hazllëkut dhe i gjithë Shqipërisë.

Historia e librit "E drejta e pashkruar", do të vazhdojë gjatë mbas përfundimit të tij. Rrethet shkencore të Britanisë së Madhe interesohen, kush e kush ta perfeksionojë atë. Me redaktimin e veprës merret elita angleze. "Leverhulmi", në radhë të parë, me lordin Guest në krye, Shoqata Mbretërore Gjeografike, Brigadieri Dejvis, autor i “Aventurës Iliriane” etj., etj.

Më 1954, Universiteti i Kembrixhit, emëron profesorin e saj, J. H. Huton, në krye të një redaksie për botimin e vëllimit të Hazllëkut.

Po atë vit, libri pa dritë, si vepër e plotë e kompletuar. Në fund, një shtojcë ku përfshiheshin "Kanunet" tona të Veriut, të përkthyera në anglisht.

Vepra do të bëjë jehonë nëpër qendra të ndryshme shkencore. U mirëprit nga etnografët. $U$ përkthye e u ribotua. U përhap nëpër botë... E ngado zgjoi vlerësim për Hazllëkun dhe simpati për Shqipërinë.

Veç te ne, s'u duk "E drejta e pashkruar". Enver Hoxha u vuri topat, daç Hazllëkut, daç veprës së saj.

... Vonë, nga fillimi i viteve '60, për Hazllëkun zënë e qarkullojnë gjithfarë legjendash... Në njërën prej tyre thuhej se Englezka qe parë në Turizmin e Durrësit me pasaportë false, por e kishin mbërthyer "heronjtë e heshtur" dhe e kishin kthyer që atë çast për në Angli... U botuan dhe dëshmi që pohonin se Hazllëku instruktonte diversantë diku nga Kazablanka dhe Frankfurti... Më e paturpshmja ndodhte në Elbasan, ku dënoheshin njerëzit, se patën hyrë e dalë te vila e Englezkës, dyzet a pesëdhjetë vjet më parë.

Ç’ ishte kjo psikozë dhe tërë kjo fushatë shpifjesh? Ku desh të dalë " $i$ paudhi” me gjithë këtë terror psikologjik? Pse e trembte kaq shumë hija e së ndjerës Margaretë?! 
... Së fundi, do të nxjerrë dhe librin "Rreziku anglo-amerikan për Shqipërinë”. Në qendër prapë Hazllëku... Diktatori vulëhumbur shpërfytyronte atë shkencëtare humane që e desh me gjithë zemër Shqipërinë dhe iu përkushtua shqiptarëve, gjersa shoi e mbylli sytë... Enver Hoxha i paturp zbulonte veten përpara gjithë botës...

Shkuan e vanë ato kohëra të diktaturës e kurrë mos u kthefshin. Po, në këto vite që na mbetën, si nuk po arrijmë gjëkundi, ta shohim " $E$ drejta e pashkruar" të botuar në shqip?... Fundja, si nuk u përmend njëherë për mirë e ndjera Margaretë?! Komunizmi veç shkatërroi.... Demokracia ç’po bën?... Nuk ka normë morale që e justifikon këtë heshtje! 